\title{
Si Marx viviera...
}

Francisco Delich

Si Marx viviera... repetía Federico Engels el 4 de Mayo de 1890 cuando «el proletariado inglés después de cuarenta años de hibernación se reincorporó al movimiento de su clase en el desfile inaugural del primero de mayo en Londres [...] doscientas mil personas llegaron al Hyde Park entre ellos una miríada de sindicatos encabezados por los estibadores y los obreros de las fábricas de gas, la Womens Trade Union League, la sociedad socialista de Blomsbury, el club Progresista de North Camberwell [...] acompañaban a Engels G. B. Shaw, el líder de los obreros del gas Will Thorne, un joven George Lansbury, el diputado socialista Robert C. Graham...(Hunt, 2011: 317)

Marx había muerto unos pocos años antes: el 14 de marzo de 1883. «El mayor pensador viviente ya no pensará más. El mundo sentirá pronto el vacío que deja la muerte de este Titán... su nombre y su obra vivirán durante muchos siglos. Así lo despidió Engels tres días más tarde en su entierro. (Schwarzschild, 1956: 460).

El siglo XX fue la apoteosis de su pensamiento y su figura. Las revoluciones rusa (1917) y China (1949), las revoluciones asiáticas, africanas y latinoamericanas enaltecieron su figura e instalaron su obra en el centro de todos los debates, entre sus seguidores y entre éstos y sus adversarios, las ciencias sociales sintieron la fuerza de su pensamiento, la historia se conmovió ante la expansión de su figura y en la segunda mitad del siglo la partió -literalmente- en la política cotidiana. Porque eso fue la guerra fría. (Delich, 2006).

A doscientos años de la Revolución Francesa, a un siglo de la muerte de Marx, estalló la Unión de Repúblicas Socialistas Soviéticas que lo había convertido en su referencia doctrinaria exclusiva (acompañado por Lenin), a sus ideas en doctrina oficial del Estado, resguardado (y íalterando?) sus papeles y manuscritos asumiendo el carácter de intérprete definitivo de sus ideas.

${ }^{1}$ Presentación del libro DELICH, Francisco (coord.), (2012), Marx, ensayos plurales, Córdoba: Comunicarte, pp. 13-36. 
La tercera internacional creada por el Estado soviético para controlar la consistencia doctrinaria y política de los estados y partidos comunistas del planeta quedó a la deriva cuando se produjo el colapso de la URRS y los distintos partidos comunistas perdieron la conducción centralizada.

Algunos entre los más importantes, como el Partido Comunista Italiano, desaparecieron o cambiaron de nombre y dejaron una tradición intelectual significativa como el legado de Antonio Gramsci en este caso. El impacto político fue enorme y en consecuencia también ideológico o doctrinario como es previsible para una teoría tan ligada (histórica y filosóficamente) a la praxis.

Como las iglesias en su momento de expansión, la extensa hegemonía de la URSS y de su partido comunista sobre el movimiento comunista internacional y sobre el propio marxismo, sobre la propia la figura de Marx, consolidó la tendencia a establecer interpretaciones oficiales expuestos a veces en forma de catecismos (preguntas y respuestas) o simplificaciones intelectuales parecidas.

Lentamente, en las tres décadas siguientes el pensamiento de Marx se independizó de Estados, movimientos, partidos políticos que lo tuvieron (o tienen) como referencia ideológica: su obra es revisitada con frecuencia y comienza a revistar entre los clásicos de las ciencias sociales (que nos interesa aquí) y la práctica política.

En ese carácter lo abordamos en este texto, actitud que nos permitió a tres antiguos compañeros de la revista Pasado y Presente, tres intelectuales argentinos (Oscar Del Barco, Héctor Schmucler y Francisco Delich) compartir y comparar nuestras visiones marxianas de los años sesenta y actuales (2010) en el marco de un programa posdoctoral de la Universidad Nacional de Córdoba.

Recuerdo, para quienes no frecuentan distinciones aparentemente bizarras, la presente: marxistas (seguidores de Marx), marxólogos (expurgadores, traductores, intérpretes, filólogos) y marxianos (lectores atentos y libres de su obra). Estos últimos, aunque menos frecuentes, mantienen interés hermenéutico o, simplemente, como aconsejaba Levi Strauss, lo releemos con frecuencia, antes de comenzar cualquier investigación. Referencias -y aventuras- similares se encontrarán en una de las mayores biografías intelectuales de Marx, en la lectura libertaria que le dedicó Maximilien Rubel (1957), un investigador exquisito responsable de la publicación en francés de La Pléiade.

Aunque innecesaria aclarar la responsabilidad personal sobre dichos e ideas de quien firma este texto, lo hago a sabiendas de compartir el espí- 
ritu crítico que nos animó medio siglo atrás, y nos sigue alentando ahora, cuando recordamos aquel sine ira et studio con el que José Aricó encabezó la crítica y autocrítica (que no se detuvo jamás) de una generación latinoamericana.

Marx vivió la lucha de la modernidad por instalarse en el planeta; la revolución social en Francia, la revolución industrial en Inglaterra apenas anunciada para el resto del planeta; el capitalismo salvaje; el embrión de la lucha de clases y la presencia del proletariado urbano industrial en algunas sociedades europeas. Marx no advirtió que estos fenómenos tenían su propia lógica aunque, un contemporáneo como él podía leerlos como ángulos de un único fenómeno singular y total a la vez. Singularidad histórica y totalidad analítica.

Marx se graduó en Filosofía (Berlín, 1842). Fue su primer y solitario contacto con la academia. Nunca fue docente ni investigador académico. Su única profesión, en el sentido de vocación y remuneración como la entendemos ahora, fue la de periodista, actividad para la que estaba singularmente dotado. Así se presentaba a sí mismo.

Puede corroborarse fácilmente. El único curriculum vitae $(\mathrm{CV})$ que Marx elaboró en su vida (hasta donde sabemos) lo compuso y escribió el 30 de enero de 1868 como adjunto a una carta a su amigo Kugelman:

Karl Marx doctor en Filosofía nacido en Tréveris el 5 de mayo de 1818.

1842-43 colaborador y luego redactor del Rheinische Zeitung (Colonia).

En 1844 publica junto con A. Ruge (en Paris) los Deutsc Französischen. Además La Sagrada Familia, Critica de la Critica Critica.

Diciembre de 1845 es expulsado de Francia por el gobierno Guizot. 1846 funda la Asociación Obrera Alemana de Bruselas; da conferencias sobre economía política; colabora en La reforme de Francia. 1847 Miseria de la Filosofía, respuesta a la Filosofía de la miseria del Señor Proudhon y también Discurso obre el libre cambio.

1848, en colaboración con F. Engels, Manifiesto del Partido Comunista.

Abril 1848 deja Francia y funda en Colonia Neue Rheinische Zeitung (junio de 1848-mayo 1849) Expulsado de Prusia escribe Dos procesos politicos.

1849 último número de Neue Rheinische Zeitung.

1849 se niega a ser confinado en Bretagne. Viaja a Londres y allí se 
radica.

1850 publica Neue Rheinische Zeitung, Politisch Ökonomische Revue (Hamburgo)

1851 colabora en la revista cartista People.

1852 El 18 Brumario de Luis Bonaparte.

1853-54 Fly Sheets against Lord Palmerston (opúsculo).

1859 Contribución a la crítica de la Economía Política

1851.1860 colaborador regular del Tribune inglesa americana en

N.York en Putnam's Magazine y en la Encilopediae americana.

1861 vuelve a Berlín: el gobierno le niega la renaturalización.

1865 publica para el Comité Central de la Asociación Obrera Internacional Mensaje a la clase obrera de Europa.

1867 El Capital-Crítica de la Economía Politica Tomo I (Hamburgo) (Marx 1969: 54-55)

Allí termina su síntesis autobiográfica, una culminación de vida, militancia política y trabajo intelectual. Marx vivirá 16 años más pero serán otros (comenzando por Engels, y sus hijas, albacea y legatarias respectivamente de su obra) quienes se ocuparan de estudiar su vida y obra, alguno de los cuales mencionamos mas abajo.

El estilo literario de Marx ha sido muy bien estudiando por Ludovico Silva un joven poeta venezolano que murió muy tempranamente y mostró justamente la relación entre escritura y carácter personal y político, entre estética de la reflexión y contenido de esa reflexión (Silva, 1978). Allí anota la arquitectónica literaria de Marx o su consideración del lenguaje científico como un arte. Pero, sobre todo, Ludovico Silva subraya el uso de las metáforas que tienen cierta importancia en las lecturas marxianas porque refuerzan y amplían -en su ambigüedad- horizontes argumentativos.

La primera lección de modernidad la recibió Marx de su primer maestro Hegel; allí estaba el triunfo de la razón sobre la sinrazón, cuyo espacio intelectual predilecto fue el conflicto entre fe / iglesias o razón / ciencia. La sociología hundiría también sus raíces transportándolo conceptualmente a la secularización. Eso fue después, en las primeras décadas del siglo XX.

La influencia inicial de Hegel no fue exclusiva: lector voraz, Marx tomaría contacto rápidamente con los iluministas franceses, escoceses e ingleses hasta configurar su propia versión de la modernidad.

Hay quien sostiene un Marx ajeno a la modernidad. Y otros que incluyéndolo en la modernidad, como los posmodernos, lo excluyen del 
debate contemporáneo. Estos últimos han agotado su entusiasmo editorial, de modo que conviene recuperar a un Marx moderno, sometido a las tensiones de la propia modernidad.

Henri Lefevbre (1962) escribió un ensayo, Qué es la modernidad, que debe contarse entre los más ricos y eruditos del siglo XX en una óptica marxiana. Allí despoja a Marx de una mochila que le cargaron algunos de sus entusiastas seguidores que necesitaban más fe que razón. (1)

Lefebvre (1962: 197) escribe a propósito: «no estamos seguros que un análisis del presente aclare completamente el futuro, es decir que ese futuro sea enteramente previsible a partir del presente $[. .$.$] por lo tanto la$ identidad entre determinación y determinismo no es una evidencia. Y un poco más adelante: «lo que caracteriza esencialmente la modernidad sería lo aleatorio (subrayado del autor) que se introduce en todos los dominios y que penetra la conciencia bajo la forma de interrogación? (ésta y las siguientes traducciones me pertenecen salvo que se indique lo contrario). Existen determinaciones, causalidades pero también áleas. Probabilidades. Así progresa la ciencia protagonista siempre invocado por los iluministas de la modernidad en su lucha contra el obscurantismo medioeval. En una carta curiosa y amistosa Kugelmal le hace notar el rol del azar a Marx, quien le responde así:

...sería un razonamiento de naturaleza mística si los 'azares' (comillas del autor) no jugasen ningún rol. Los casos fortuitos entran naturalmente en la marcha general de la evolución y se encuentran compensados por otros azares. Pero la aceleración o desaceleración del movimiento [revolucionario] dependen bastante de semejantes azares entre los cuales figura el azar del carácter de los jefes llamados a conducir el movimiento. (Marx: 1952:82)

Azares menores no alterarían para Marx el carácter científico de su obra.

La modernidad-sigue Lefebvre-sociológicamente pensada se pone en evidencia a través de sus contradicciones: angustia de soledad y aislamiento en la vida cotidiana, contradicción entre la planetarización y la individuación, diríamos ahora entre la socialización obligatoria en la red y la vida privada, entre la necesidad y la apropiación del deseo (1962:189)

Esa visión de un mundo enajenado (alienado, para escribirlo como Marx) es la primera preocupación filosófica que recorre los manuscritos parisinos, especialmente el tercero. Es una reflexión, sobre la modernidad pero no su apología. En particular porque una lectura latinoamericana 
confirma la incidencia histórica del romanticismo estético y crítico de Baudelaire, como sostiene Lefebvre en un paralelo; pero también Echeverría o Martí en nuestro continente, lectura sociológica y poética.

Un romanticismo que se aleja de la razón, pero que nutre la causa de la independencia aquí y de los trabajadores industriales allá. Dos caminos hacia la emancipación. Regresaremos más adelante a este punto tan decisivo en los años sesenta. (2)

Testimonios de aquel primer impacto intelectual (la modernidad) y su ruptura (en la versión Hegel) se encuentran en otros textos juveniles (Cuestión judía, Feurbach) y sus rupturas personales con Bauer y otros ex compañeros)

Autodidacta que leyó y escribió correctamente en ingles (su primer discurso data de 1853) y francés (escribió directamente en francés su respuesta a Proudhon la Miseria de la Filosofía), al final de su vida trató de aprender ruso acuciado por conocer la cuestión agraria y sostener su diálogo con los intelectuales eslavos, entre los cuales Vera Zasulich la única que asiste a su entierro de pocas personas.

La cuestión agraria fue siempre el punto más débil en la construcción teórica de Marx, que tomó de Ricardo la distinción entre renta absoluta y relativa, aunque era algo inconsistente con su ley del valor.

La comuna rusa, como la zadruga eslava en general, le planteaban problemas no solamente analíticos sino estrictamente políticos ¿era posible un tránsito sin escalas de aquellas comunas al comunismo? Shanin recupera a Chajanov y con él la cuestión de la organización comunal, un siglo después, como una interrogación pero también asimilables a situaciones comunales, en antiguas tradiciones americanas de aztecas, quechuas y aymaras en América. (3)

Chajanov tendrá un cierto impacto los años setenta en Sudamérica, que luego se perderá: en parte, por el ingreso del capitalismo; en parte, por las reformas agrarias y por la sobrevivencia y el reconocimiento de estas formas antiguas de producción, como los ejidatarios mexicanos después de la revolución de las primeras décadas del siglo XX o de la revolución peruana (1968). He dedicado un análisis mas extenso en Repensar América Latina (Delich, 2004) (4)

Stalin lo resolvió negativamente en un genocidio bárbaro de campesinos durante su gobierno de la URSS. El campo fue subordinado al crecimiento industrial y los campesinos subordinados a la conducción partidaria. 
Apagados los ecos del llamado postmodernismo o posmodernidad, la modernidad retoma sus discusiones -como lo están mostrando Habermas, Giddens y Touraine en la Sociología- y en su centro Marx ocupa un lugar preponderante. $\mathrm{O}$, si se prefiere, Marx forma parte del debate inacabado sobre la modernidad. Se encuentra ahora cotejado y discutido, por ejemplo junto a su contemporáneo Alexis de Tocqueville; o junto a Hanna Arendt como lo hace Reinhardt (1997) para reunir tradición e innovación. Nadie pudo imaginar un debate sobre el arte de ser libre como el que inaugura a esas tres líneas de pensamiento. $\mathrm{O}$ en el muy sugerente texto de Marshall Bermann (2003), que releyendo el manifiesto comunista recupera un Marx lector moderno de la contemporaneidad.

Estas revoluciones europeas no eran las únicas: en América se producían por entonces las primeras revoluciones anticoloniales, comenzando por los Estados Unidos de Norteamérica; y a continuación, por las antiguas colonias ibéricas. Ésta convergencia histórica americana se erosionaría en las siguientes décadas, separando a los sajones protestantes del norte de los hispano parlantes católicos del sur, comenzando la historia propia del centro-sur de América que los franceses bautizarían como latina para acercarlas más a su propia revolución.

El pensamiento de Marx trascendería a los Estados Unidos rápidamente como una versión del socialismo que defiende la libertad de prensa y la democracia contra la monarquía alemana, en particular cuando Marx se convierte en corresponsal del periódico New York Tribune. Pero recién a fines del siglo XIX (muerto Marx) ingresaría en América Latina de la mano de la social democracia alemana triunfante ideológicamente con Engels (aún con vida) como referente, pero con El Capital como bandera. Juan B. Justo funda el Partido Socialista Argentino en 1896 y traduce el Tomo I de El Capital. (5)

Una historia paralela de las repercusiones del pensamiento de Marx en Europa y las Américas ayuda no solo a esclarecer la identidad latinoamericana sino mostrar historias conceptuales, articulaciones teóricas -como veremos luego- sustanciales que un análisis prolijo pone en evidencia.

Y nos pone también en camino de una lectura más original de su obra, en un momento excepcional donde se altera el status epistemológico de la América Latina. Antes punto de referencia histórico-empírico para la validación (confrontación) teóricas europeas, se convierte ahora en productor de articulaciones conceptuales.

Pero la modernidad no es solo la razón, también se define en la Sociología como incluyendo dos fenómenos conexos relevantes para la 
comprensión de los siglos XX y XXI sobre los que volveremos: la tecnología, subproducto de la ciencia que tanto apasionó a Marx; y la urbanización, subproducto del capitalismo. Ambos atributos tomarán distancia de sus orígenes y encontrarán sus propias lógicas cuando las sociedades alcancen grados de complejidad creciente. (6)

Marx pensó que había descubierto una lógica universal capaz de explicar el capitalismo y todos los sistemas sociales anteriores y posteriores: la implacable lógica que terminaría con su propio derrumbe, lógica impersonal y sistémica, fundada en la ley del valor, piedra basal de su sistema de ideas, origen de las clases sociales en el capitalismo y de la lucha inexorable y final entre ellas. La teoría del derrumbe atribuida a Marx fue definitivamente sepultada por el Partido Comunista italiano en los años setenta aunque quedó latente el abstracto principio de determinación en última instancia. (Lefebvre, 1962).

Descubierta por Darwin la lógica de la evolución biológica de la humanidad en su célebre Origen de las Especies, a Marx solo le cabía completar el análisis de la evolución social de la humanidad. La ciencia positiva, capaz de establecer una legalidad social tan inmutable como las leyes de la naturaleza (cuyo más alto ejemplo había mostrado Newton en su enunciación de la ley de la gravedad) constituía su modelo intelectual, su parámetro de verdad histórica y epistemológica.

La dialéctica de la naturaleza se agregó a la dialéctica de la sociedad para avanzar científicamente en el conocimiento del mundo y la sociedad, una cosmovisión materialista, ajena a dioses e ignorancias.

La elaboración de legalidades universales que construían las ciencias de la naturaleza definía el propio carácter de la ciencia; aunque ya se había inventado el cálculo probabilístico, Marx no lo tuvo en cuenta. Su noción de ciencia era ajena al azar, el conocimiento verdadero era el producto de la indagación científica. Que se expresaba en esas leyes universales, en determinaciones absolutas e inmodificables. Alguno de sus apólogos irían más lejos: en los fenómenos sociales habría una última instancia, una determinación inapelable: el inevitable derrumbe del capitalismo, la inevitable lucha de clases entre proletarios y burgueses.

Ajena al pensamiento de Marx, nuestra región no era en cambio ajena a las luces de la modernidad que Marx compartía y difundían los hombres de la independencia. La ciencia era condición de libertad para José Gaspar Rodrigues de Francia fundador del Paraguay o la consigna de A. Comte que ondea aún (2010) en la bandera brasileña (Ordem e Progresso), de Porfirio Díaz en México, de los argentinos Castelli y Monteagudo. 
La ciencia, como quería Comte, era no solo capaz de explicar sino de prever: esa era su función mayor pero también la prueba última de su legalidad universal. La modernidad y el positivismo iban de la mano en la ciencia y la política para la liberación colonial en América Latina y la liberación de la humanidad en Francia, Gran Bretaña y Alemania.

Esta asincronía histórica entre el pensamiento europeo de la modernidad y su recepción y elaboración latinoamericanas, la tardía recepción de Marx y el socialismo científico, y el no menos tardío reconocimiento de las especificidades de la región en el pensamiento europeo, señalan distancias no solamente geográficas sino conceptuales. De esto se trata precisamente.

Marx se traslada a París con su mujer (unos años mayor) con quien compartirá su vida de perpetuo exilio hasta su madurez estable en Londres. En París se vive tanto la descomposición como la emergencia de una nueva sociedad. Marx tiene 25 años, se instala como co-director de los Deutsc Französischen por los que recibe un sueldo razonable. La revista quebrará muy pronto, seguirá una polémica con Ruge (quien había aportado el capital) y dejará Marx en París sin empleo.

Sería el comienzo de una vida de privaciones y dificultades económicas que no cesaría jamás y en algunos momentos tendría aristas dramáticas.

Por aquellos años la revolución forma parte de la agenda política. La revolución marca el espíritu del tiempo de ambos lados del atlántico. Marx no registra la experiencia de los Estados Unidos de Norteamérica que un aristócrata francés, Alexis de Tocqueville analiza como pocos en su De la démocratie en Amérique. El libro aparece en 1835 y pocos le asignan valor predictivo ni prestan atención a la primera democracia federal que se inaugura en el planeta.

No hay sitio en el debate europeo para el otro lado del atlántico. Ha llegado el ocaso de las monarquías absolutas legitimadas en Dios y por el Dios cristiano, la separación de los poderes celestial y terrenal, pero aún se discute el origen de la nueva legitimidad.

Marx no es el único que lo ignora. Tocqueville no será nunca reeditado ni discutido como lo merece hasta un siglo después. Sin embargo, es leído y apreciado por un joven intelectual argentino que retomará sus ideas 
y las plasmará en 1853 en la constitución nacional. Se llamaba Domingo Faustino Sarmiento y era un contemporáneo de Marx.

Para ser justos con Marx y la Sociología, ignorar a Tocqueville no significa ignorar América. Por el contrario, Rubel descubre que en 1843 el recién graduado Marx encuentra un texto de un escocés apellidado Hamilton que no solo destaca las virtudes del nuevo régimen sino que le habría mostrado las potencialidades revolucionarias de la democracia federal recién estrenada e Estados Unidos. (Rubel, 1974: 175).

Conviene señalar desde ahora un tema inexplorado o subestimado en la obra de Marx: la relación entre los conceptos de revolución y transformación social y entre esta y los regímenes políticos democráticos que Rubel, y otros libertarios como él, abordaron en la década de los sesenta recuperando los derechos del hombre proclamados por la Revolución francesa.

El joven alemán expatriado está en la capital de la revolución que se sueña capital del mundo. Allí termina su alejamiento intelectual de Hegel no sin reconocer el carácter revolucionario de su Fenomenología ni de su Lógica, como lo atestigua en sus célebres manuscritos a los que me refiero inmediatamente.

Los que ahora simplemente conocemos como manuscritos fueron escritos entre 1844 y 1846. Era un proyecto de libro que Marx no completó, y que contiene un prólogo seguido de tres capítulos que se conocieron tardíamente (1932) pero cuya valorización política fue más tardía aún, a comienzos de los años sesenta.

La crítica como mirada como posición intelectual, como metodología quedó asociada para siempre a su nombre en las ciencias sociales. La escuela de Frankfurt es su testimonio contemporáneo. Pero menos visible en América Latina la resonancia de Ernesto Guevara en relación a Marx y su contribución a una relectura. En particular el romanticismo revolucionario como señala Lefevbre en relación a Sthendal o Malraux para nuestra generación que reactualiza la revolución en la guerra civil española (19361939).

Los Manuscritos de Marx (como se los conoce), de 1844, fueron publicados por primera vez en Alemania en 1932 en Der Historiche Materialismus. Die Frühschriften, por Lanshut y Mayerl en Leipzig. Estos ma- 
nuscritos de Marx cuya guarda entregó a una de sus hijas y a Engels, fueron a parar a Moscu. Los dirigentes soviéticos recién dieron a conocer una versión definitiva (sic) dos décadas después. Antes, durante o más tarde desaparecieron varias páginas.

En 1962 apareció en francés una edición presentada, traducida y comentada por Emile Bottigelli, en las Editions Sociales, como parte de las obras completas de Marx.

Como señala con razón Botigelli (1962: VII): «raramente un texto ha sido tan maltratado ha sido objeto de comentarios tan diversos, ha dado lugar a tantas controversias como los Manuscritos de Marx de 1844». Algunos - prosigue Botigelli- creyeron encontrar un Marx ético, humanista centrado en una teoría de la alienación, otros un Marx joven filosofo distinto al Marx economista maduro; políticamente el Marx de los Manuscritos estaría -para terceros- próximo de los social-demócratas.

Leí ese mismo año aquella versión de los manuscritos especialmente sus reflexiones sobre la alienación pero en una perspectiva menos filosófica o propiamente sociológica, porque en aquel momento seguía de cerca la elaboración de una sociología de la vida cotidiana que encaraba Henri Lefebvre en sus cursos.

Aquel año 1963 apareció en Córdoba Pasado y Presente dirigida por Oscar del Barco y Aníbal Arcondo: conocía a ambos de la militancia estudiantil aunque desde veredas opuestas. Me reencontré con Del Barco en Europa cuando preparaban el número siguiente; Del Barco había tenido acceso a los Manuscritos y preparaba un artículo sobre los mismos que apareció el año siguiente (1963) en la revista. Los Manuscritos fueron nuestro punto de encuentro.

Me ofreció incorporarme al Consejo de Redacción. Sus miembros habían sido expulsados del Partido Comunista Argentino como castigo por la publicación de la revista o por su adhesión a las tesis de la revolución cubana. Fui el único miembro no comunista de aquella redacción, según supe después.

Aquel encuentro y aquella incorporación marcaba también el espíritu del tiempo, donde la revolución envuelve, contagia y traspasa vidas personales e ideas. Los Manuscritos eran reivindicados como un alarido contra las ortodoxias: el ajuste de cuentas final que los jóvenes comunistas realizaban contra las antiguas burocracias estalinistas.

La revolución se había desplazado en América de Moscu a La Habana; Lenin importaba menos que el comandante Guevara. Los Manuscritos podían leerse en una clave diferente: el hombre nuevo que anunciaba Gue- 
vara en Cuba estaba en aquellos manuscritos, tenía raíces teóricas profundas, más profundas que Stalin o el poder soviético o el propio PC: estaba en las entrañas de la revolución que el joven Marx lideraba como nadie.

Aquellos textos marxianos se constituirían en un puente que libertarios, socialistas y revolucionarios de todas partes beberían para refrescar ideas. Había una revolución distinta a la soviética y a la china, que convocaba a intelectuales como el exiliado Marcuse o el joven sociólogo C. W. Mills que acompañaban los nuevos tiempos en América del norte, como Sartre en Francia; y los menos conocidos, pero apasionados intelectuales latinoamericanos ajenos a estos manuscritos, que podían repensar su propia sociedad a partir de esta revolución capaz de traspasar los límites de jacobinos y bolcheviques, que reunía la razón científica al romanticismo.

No era otra cosa el romanticismo revolucionario que los cubanos desparramaban por el planeta a comienzos de los años sesenta.

Volvamos a los Manuscritos. Se trata de tres cuadernos: el primero está dedicado a los conceptos de salario, capital y renta de la tierra. Consta de 36 páginas. Marx establece un diálogo crítico con A. Smith y más amigable con D. Ricardo. Con este último se profundizarán hasta la publicación del primer tomo de El Capital.

El segundo manuscrito está dedicado a la oposición de capital y trabajo, y a la propiedad de la tierra y el capital. Se han recuperado apenas 4 páginas de las 43 , según la numeración en romano del propio Marx. El tercer manuscrito consta de de 68 páginas de las cuales las 23 últimas están vacías. Entre corchetes se indica propiedad privada y trabajo. Puntos de vista de mercantilistas, fisiócratas, de Adam Smith, de Ricardo y de su escuela que incluyen sus reflexiones ligadas a la alienación.

Como se advierte Max estaba cimentando su crítica de la economía política, afirmando el carácter científico de su obra y articulando conceptualmente la división del trabajo a una forma de explotación -el capitalismo- cuya expresión social es la alienación de los trabajadores. Recién en 1857 Marx presentaría una visión completa en la Introducción a la crítica de la Economía política.

Cuatro años después Marx y Engels publicarían el con razón célebre Manifiesto Comunista (1848), que merece una atención mayor durante el siglo y medio siguiente. Entre aquellos Manuscritos de 1844 y este Manifiesto de 1848 aparece un libro que merece una atención que no tuvo a largo del siglo XX. Me refiero al libro de Federico Engels La situación de la clase trabajadora en Inglaterra (1845) que dedica los trabajadores ingleses con una presentación escrita directamente en esa lengua. 
La de Editions Sociales de Paris (1960) que utilizo tiene un prólogo de Eric Hobsbawm que vale pena recorrer por varias razones: para rescatar la importancia de Engels en la formación del pensamiento de Marx, el valor intrínseco de los estudios de campo y su repercusión en América Latina.

El estudio lo recuperó y enriqueció J. Bialet Massé en 1905 en su conocido Informe sobre las clases trabajadoras el más antiguo ensayo de Sociología del Trabajo en Argentina y América Latina y que, junto con los estudios de Le Play, y el ya señalado de Engels, deben incorporarse a los antecedentes de la mejor Sociología.

A partir de entonces la obra de Marx fue examinada de otra manera. Una explosión de marxismos antiguos y recientes se aproximaron e incluyeron en los debates. La comprobación de los crímenes de Stalin (1956, durante el XX Congreso del Partido Comunista de la Unión Soviética) fracturó de manera definitiva a los hasta entonces monolíticos partidos comunistas.

El genocidio de diez millones de campesinos desató el cuestionamiento del régimen primero y de sus responsables teóricos. Para algunos, Lenin en primer lugar, la teoría de la dictadura del proletariado luego, pasando por las transiciones del capitalismo al socialismo, la democracia socialista y otras cuestiones.

Aquel congreso marcó el comienzo de una reapertura del debate entre marxistas europeos y latinoamericanos y está en el origen de la revista Pasado y Presente y de las relecturas de Marx que comento.

La revolución tomaba otros caminos y la lectura de sus antecedentes no hacía sino justificarlos: la subjetividad tomaba su revancha sobre la objetividad, el voluntarismo sobre la tradición, el coraje de la juventud sobre el anquilosamiento burocrático

En 1976 apareció inicialmente en polaco, y en 1978 en inglés, el estudio de Kolakowski, Main currents of marxism (2005), considerada una de las obras más completas dedicadas a las corrientes marxistas publicadas hasta finales de la experiencia soviética; no contiene ni una sola mención de los marxistas latinoamericanos.

Si bien Marx fue introducido en nuestra región a fines del siglo XIX por dirigentes afines a la social democracia alemana, como se indico para la Argentina, luego de la instauración del régimen soviético (1917) la fundación del partido Comunista argentino (1921) escindido de aquel, comenzó una disputa acerca de su legado intelectual y político. 
Estas lecturas de Marx y su obra se actualizaron en términos políticos y académicos con la caída del régimen soviético, que había oficializado su pensamiento (la lectura e interpretación) a nivel estatal para el resto del planeta.

De tal modo que Marx y Partido Comunista de la Unión soviéticaTercera Internacional fueron identificados en el interior de la guerra fría que se desató a partir de 1948 y hasta 1989. Esta es -probablemente- una de las razones por las cuales Marx no fue leído en América Latina sino a través de los partidos comunistas locales y en consecuencia fue visualizado en Europa como mera extensión de los partidos comunistas en el poder del este europeo.

Sin embargo, lecturas diferenciadoras fueron violentamente reprimidas por los respectivos comunistas locales, como en Francia donde fueron expulsados del Partido Comunista sucesivamente los filósofos Henri Lefebvre, Roger Garaudy y Louis Althuser, entre 1960 y 1980, por interpretaciones democráticas (por llamarlas de algún modo) aunque cada una de ellas tenía una mirada distinta de Marx y su obra. Pero en su conjunto ofrecían una lectura de Marx distinta -radicalmente distinta- a la oficial del partido comunista soviético. Y todo ello sin contar la lectura de Antonio Gramsci, fundador del Partido Comunista Italiano, y Mao Tse Tung fundador del Partido Comunista Chino. Volveremos mas adelante sobre Marx en América Latina.

Prosigamos con Marx en París escribiendo sus borradores, que no son sino apuntes de sus lecturas (Marx tuvo a largo de su vida como método de trabajo la elaboración de resúmenes, abstracts, de sus lecturas que no estaban obviamente destinados a ser publicados).

Marx encuentra en sus lecturas textos de Flora Tristan, que había nacido en París de padre peruano y madre francesa en 1803 y murió en Bordeaux en noviembre de 1844. Cuando ocurre la prematura muerte de Flora, Marx está recién llegado París, ella había logrado dejar un testimonio existencial de la situación obrera y femenina. Y es probablemente la primera en utilizar el término proletario para definir a los trabajadores ingleses predicando la unión obrera, sosteniendo que la emancipación de los trabajadores será obra de los propios trabajadores.

El año siguiente, 1845, Marx contará con el aporte invalorable del libro de F. Engels (situación de la clase laboriosa) pero el libro de Flora Tristan es un antecedente que Marx conoce y comenta en sus Manuscritos (Rubel, 1957), aunque no favorablemente. Respeta la intención pero no comparte el razonamiento. 
Flora es peruana, regresa al Perú en busca de una fortuna que le corresponde (por herencia de su padre): no la consigue pero descubre América Latina. En París, sus padres reciben con frecuencia a un muy joven Simon Bolívar y a uno de sus maestros (y maestros de la independencia americana Simón Rodríguez) Curiosamente no tendría en cuenta la condición femenina ni sus luchas, ni tampoco a Simon Bolívar a quien dedicaría in artículo despectivo.

La condición femenina en sí misma, su asimetría en relación a la estructura patriarcal de la sociedad, no es considerada. En los Manuscritos Marx reconoce a la mujer su condición femenina pero para completar la idea de un hombre ligado a la naturaleza. Ella es su necesario complemento.

En aquellos años las revoluciones que se preparaban en Iberoamérica tras la ocupación de España por Napoleón Bonaparte no interesaban a Marx. Ni tampoco la condición femenina en el capitalismo: en la revolución proletaria que imaginaba no habría disonancias.

En cierto modo para quien pensaba en términos universales, la emancipación de una clase social tan universal como el propio capitalismo $\mathrm{Na}$ ción y Estado eran propuestas irrelevantes, desde el punto de vista de una teoría universal de la historia. Como veremos, ambos conceptos convertidos en instituciones históricas se volverán obstáculos para la penetración del pensamiento de Marx en América Latina.

Por su parte Flora Tristan es recogida en la posteridad como precursora de las luchas femeninas, pero no siempre como precursora de las luchas obreras y como antecedente relevante entre los socialistas de comienzos del siglo XIX.

Pero el año definitivo será 1848.Una gran rebelión social en París, revueltas en Milán y Berlín no son para Marx (y Engels) sino la evidencia de tiempos revolucionarios. Escribe junto con su amigo definitivo Federico Engels el Manifiesto Comunista que recorrerá -literalmente- el mundo durante el siglo siguiente y prosigue en la primera década del siglo XXI.

Marshall Berman escribió a partir de una frase del manifiesto, Todo lo sólido se desvanece en el aire, un ensayo tan rico y provocador como pocos. Reunió a este Marx con el Fausto de Goethe: «me ayudó a ver cómo las cosas malas y buenas del mundo podían surgir del mismo lugar, cómo el 
sufrimiento podía ser fuente, cómo el pensamiento radical podía escapar a los dualismos y crecer en visión y energía para llegar a tiempos mejores.» (Berman, 2003: 87).

La frase del Manifiesto seguramente inspiró al antiguo comunista Baumann en su hipótesis de sociedades líquidas para caracterizar las sociedades actuales. La inestabilidad de las sociedades mutantes como las nuestras son manifestaciones de las raíces de la modernidad, para señalar una banalidad que no lo era 1848. Pero el Manifiesto es más, mucho más que la modernidad, no se reduce a ella, la contiene y la instala en otro lugar, la muestra como posibilidad y como exigencia.

Berman subraya con razón el largo elogio que Marx y Engels dedican a la burguesía que «ha desempeñado un papel altamente revolucionario» más aun señalando que «la burguesía no puede existir sino a condición de revolucionar incesantemente los instrumentos de producción y, por consiguiente de, las relaciones de producción con ello todas las relaciones sociales» (Marx y Engels, 1986: 37-38); prosiguen en este reconocimiento «mediante la explotación del mercado mundial, la burguesía dio un carácter cosmopolita a la producción y al consumo de todos los países ha sometido el campo a la ciudad [...] la burguesía con su dominio de clase que cuenta con solamente un siglo de existencia creando fuerzas productivas más abundantes y grandiosas que todas las generaciones pasadas juntas». (Marx y Engels, 1986: 39-40).

Las citas abundan y muestran a un Marx conciente de los cambios en curso, lo que incluye la irreversible globalización de los mercados a partir del descubrimientos de América y así lo establece explícitamente. El Manifiesto es un panfleto al estilo de sus similares del siglo XVIII y XIX que contiene en este caso pistas sólidas sobre la conformación de un pensamiento, tanto como expone la coyuntura ideológica partidaria en su segunda y tercera partes.

La edición que utilizo tiene una versión supuesta de unos borradores que Engels habría utilizado y que en esta edición se convierten textualmente en un catecismo de preguntas y respuestas acerca del comunismo... oficial naturalmente. Si lo señalo es, justamente, para mostrar el uso tendencioso - cuando no directamente falso- que los partidos comunistas hicieron de los textos de Marx y Engels, durante la hegemonía de la Unión Soviética.

Fracasan las revoluciones que Marx espera, peor todavía: se siguen restauraciones avaladas por el voto ciudadano $\mathrm{El}$ acceso al poder de Luis Napoleón Bonaparte en Francia le sugiere a Marx una reflexión y un texto 
que se encuentran entre los más logrados (en términos actuales de ciencias sociales) me refiero a El 18 brumario de Luis Napoleón Bonaparte (en adelante 18 B.).

No suele tenerse en cuenta el trabajo periodístico de Marx. En su exaltación, algunos imaginan una obra homogénea sin altibajos en estilos y contenidos. Sin embargo, la obra periodística más ligada a la militancia política permite un encuentro distinto.

El $18 \mathrm{~B}$. es un ensayo de análisis de coyuntura que completa el $\mathrm{Ma}$ nifiesto Comunista que junto con Engels habían lanzado tres años antes; el primero es, como se dijo, un panfleto militante en medio de lo que imaginan una coyuntura propiamente revolucionaria, dirigida a los trabajadores y al movimiento socialista europeo.

Tres años después la derrota de la rebelión francesa se salda con la elección de un príncipe presidente Luis Napoleón Bonaparte, al frente de una coalición electoral que describirá como partido desorden.

Cada uno de los capítulos fueron escritos como notas periodísticas para una publicación americana que se proponía editar su amigo Weidemeyer. Finalmente no se publicó, pero aparece después en los Estados Unidos como un folleto on revolution, luego traducido y editado en Europa.

Este análisis, que se puede leer como una ampliación local de $E l$ Manifiesto Comunista, se completa con La guerra civil en Francia donde termina el ciclo político de Bonaparte que había comenzado veinte años antes.

En medio aparece el tomo I de El Capital al que nos referimos más adelante, pero la coherencia entre los textos políticos periodísticos y este texto analítico-histórico elaborado a lo largo de un cuarto de siglo es completa.

El hilo de todos los textos mencionados es invariablemente la lucha de clases y la irreductibilidad de su enfrentamiento en El Manifiesto Comunista, sus matices en la historia francesa y sus fundamentos en El Capital.

El análisis estructural de El Capital y el análisis coyuntural del $18 \mathrm{~B}$. tanto como La guerra civil son claramente diferenciables pero muestran una coherencia total con -a mi juicio- la definición misma de uno y otro tipo de análisis. 
Los análisis de estructura y coyuntura en las ciencias sociales incluyen, razonan las mismas variables: solo varía el tiempo y el espacio (Delich, 1971). La coherencia analítica justamente se obtiene con la identidad de las variables y el acento cualitativo sobre lo cuantitativo.

Los dos textos coyunturales tienen la lucha de clases como hilo conductor, como núcleo analítico para explicar la coyuntura política, pero el enfrentamiento estratégico de burgueses y proletarios, que marca estructuralmente la historia, es un escenario más concreto y limitado en el tiempo y en el espacio.

La burguesía ascendente se enfrenta con la aristocracia financiera, se alía en alguna de sus batallas con la pequeña burguesía y aun con proletarios, con clases que han triunfado y heredado al mundo feudal como los campesinos; las clases sociales no se corresponden estrictamente con movimientos y actores políticos -no siempre- al menos.

La disputa política sigue los avatares de la lucha de clases pero no se identifica: porque las clases no son tampoco actores homogéneos y en la coyuntura aparecen nítidas las fracciones de clase como se puede apreciar.

Las coyunturas son más complejas, densas, los detalles cuentan, los actores principales de disfrazan o mimetizan, el coro es volátil cuando las contradicciones se agudizan en el corto plazo.

Es sin duda una de las razones por las cuales algunos tratarán de explicar la emergencia política del general Perón y de su movimiento en Argentina un siglo después como un fenómeno similar encarnando el bonapartismo, el momento en que fuerzas políticas son capaces de coincidir en convergencias de clases destinadas a enfrentarse. Pero también en el común privilegio que ambos (Perón y Bonaparte) otorgan a los ejércitos, partícipes y soportes de sus gobiernos como de sus concepciones propiamente políticas. La integración conceptual y política de las Fuerzas Armadas al proyecto de gobierno es tan estratégica como la participación popular en ambos casos.

A ninguna clase social dedica Marx tanto espacio y detenimiento como a los campesinos, responsables del triunfo electoral de Luis Bonaparte. Un excurso. Para Marx el campesino, la clase campesina si así pudiese denominarse será una incógnita, un desafío intelectual y un obstáculo político perpetuo. Demasiado complejo históricamente, demasiado singular el origen de la renta agraria, demasiado conservador en sus costumbres e ideología frente al mundo nuevo, a lo moderno, a la modernidad.

Marx, hemos reiterado, era un hombre de la modernidad fascinado por el progreso, por la ciencia y la tecnología que imaginaba lo que correc- 
tamente intuía: lo que Julio Verne anticipaba como proeza y aventura individual, Marx lo predicaba para la humanidad.

Marx, digamos de una vez, no solo no apreciaba el mundo rural: era, a su juicio, parte del pasado de la humanidad, era idiota (textual) y los campesinos no tenían conciencia de clase ni podían tenerla, eran-escribirá-como una bolsa de papas, átomos, individuos reunidos carentes de visión futura. Con una identidad negativa fundada en la defensa del statu quo y los intereses inmediatos. Eso explicaba su voto masivo por Bonaparte.

«El poder del Estado - escribe Marx- no planea en el aire; Bonaparte representa una clase bien determinada, incluso la clase más numerosa de la sociedad francesa, esto es los campesinos parcelarios». (subrayado por Marx [1963:104]).

Citemos con cierta extensión esta antropología campesina que explica el voto y la adhesión a un príncipe, a un orden social:

Los campesinos parcelarios constituyen una masa enorme que viven todos en la misma situación pero sin estar unidos los unos a los otros por relaciones variadas. Su modo de producción los aísla unos de otros en lugar de conducirlos a relaciones recíprocas. Este aislamiento se agrava por el mal estado de los medios de comunicación en Francia y por la pobreza campesina. La explotación de la parcela no permite ninguna división del trabajo, ninguna utilización de métodos científicos y en consecuencia ninguna diversidad de desarrollo, ninguna diversidad de talentos, ninguna riqueza de relaciones sociales.

Cada familia campesina es autosuficiente, produce la mayor parte de lo que consume y se procura así sus medios de subsistencia más por intercambio en especie que en la sociedad. La familia, el campesino, la parcela. Al lado otra parcela, otra familia, otro campesino. Un cierto número conforman un caserío, un cierto número de caseríos conforman un departamento. Así la gran masa de la nación francesa esta constituida por una simple adición de tamaño poco más o menos de la misma manera que una bolsa llena de papas conforma una bolsa de papas [...] pero ellas no constituyen una clase en la medida en que los campesinos parcelarios la similitud de intereses no crea entre ellos ninguna comunidad, ninguna identidad nacional, ninguna organización política. (Marx, 1963: 104-105) 
La guerra civil en Francia (1871), si bien escrita por Marx corresponde a dos comunicados de la Asociación Internacional de Trabajadores (fechados ambos en Londres, uno el 9 de setiembre de 1870 y el otro en 30 de mayo de 1871).

La comuna de Paris que ha conmovido Europa será derrotada y muchos de sus militantes masacrados. Marx había señalado los límites (incluso militares) que su antiguo adversario Proudhon -socialista libertarioestableció para aquella insurrección.

Sin embargo Marx y la Internacional escribían: «Si la comuna fue entonces la representación visible de todos los elementos sanos de la sociedad francesa y en consecuencia el auténtico gobierno nacional, fue al mismo tiempo un gobierno obrero y en tal título audaz campeón de la emancipación del trabajo».Y el párrafo concluye con esta formidable metáfora: Bajo la mirada de la armada prusiana que había anexado dos provincias francesas, la comuna anexaba a Francia a los trabajadores del mundo entero.» (Marx 1952:55).

Es la pluma suelta del político la que escribe. El primer mensaje termina con un viva la República. Las contradicciones de clase sobre las que había reflexionado veinte años en $18 \mathrm{~B}$. están atenuadas, la guerra franco prusiana ha sido un gran desafío teórico y político; la comuna de Paris por conducida adversarios, otro. La Segunda Internacional, que consolidarán en Alemania Liebnecht y Kautski apoyados por Engels, está en el origen de los partidos socialistas europeos y también latinoamericanos como en Argentina, Uruguay y Chile a fines de ese siglo.

Es que unos años antes, en 1867, apareció el primer tomo de $E l$ Capital e instala a Marx casi inmediatamente dentro y fuera del socialismo como una figura intelectualmente respetable. Pero también sus opiniones políticas, aunque minoritarias, son valoradas.

Marx publicó en vida un único tomo de El Capital (de los cuatro previstos). Los dos tomos siguientes serán publicados bajo la responsabilidad de Engels; y el cuarto (Teorías sobre la plusvalía) ya fallecidos Marx y Engels. No me referiré aquí ni a este texto ni tampoco a los Grundrisse, borradores útiles para explicar la formación económica de Marx, que no son decisivos para lo que interesa aquí, aunque útiles para comprender mejor la formación económica de Marx 
En un postfacio escrito para la segunda edición que Marx fecha el 24 de enero de 1873 en Londres, anota:

...en la primavera de 1872 se publicó en San Petersburgo una excelente traducción rusa del Capital. La tirada de 3.000 ejemplares se halla casi agotada.

Ya en 1871 el señor N. Sieber profesor de economía política de la Universidad de Kiev en una obra titulada Teoria Zanosti i Kapitala (La teoría del valor y del capital en D. Ricardo), había informado sobre mi teoría del valor, del dinero y del capital, en sus rasgos fundamentales, presentándola como el necesario desarrollo de Smith y Ricardo. El lector occidental de este sólido libro se encuentra sorprendido ante la consecuencia con que el autor sabe mantener su punto de vista puramente teórico (Marx, 1980: XXI)

Marx situaba su obra en el interior del análisis económico, aspiraba a una auténtica ciencia social, una revolución conceptual que partía de tres premisas metodológicas: la ruptura de las apariencias, el concepto de dominación y poder político asociado al capital, su acumulación y circulación, y la investigación empírica.

La estrecha relación que Marx reconoce con Ricardo, el desprecio por Malthus y de su crítica a Ricardo lo instala en el corazón de la Economía clásica y también de la Sociología clásica en relación a Comte, Saint Simon o Proudhon. ¿Puede ir más allá de la teoría del valor trabajo? Antonio Gramsci se pregunta y le pregunta a través de su cuñada a su amigo Piero Sraffa que está reuniendo la obra completa de D. Ricardo en la Universidad de Cambridge (invitado y supervisado por J. M. Keynes) (Potier, 1994:143).

Debemos recordar que Sraffa ha sido militante comunista y compañero de Gramsci en la fundación del Partido Comunista Italiano, y el amigo que proveía ayuda a su familia durante la cárcel, a él mismo y quien enviaba los libros que Gramsci pedía.

No obstante Sraffa discutirá con su amigo encarcelado sobre los supuestos de Marx en un artículo conocido sobre la producción de mercancías por medio de mercancías una de los mayores y sólidos cuestionamientos académicos a la ley del valor.

Sin la ley del valor toda la teoría de las clases se derrumba. Sraffa lo sabía. Hijo de una familia judía -perseguido por Mussolini no solamente por esta condición sino también por su adhesión al partido comunista- de sólida posición económica, se exiló en Inglaterra invitado por el propio Keynes y dedicó prácticamente su vida a la obra de David Ricardo. 
La lay del valor que está en la génesis del capital y su circulación tiene su origen en Ricardo (teoría del valor trabajo), pero Marx va mas allá: estima que existe un plus valor del que es despojado el trabajador, y funda la estratificación social y dominación de clase (de allí su condición irreductible): si la ley del valor no tiene carácter científico tampoco lo tiene la inevitabilidad de la lucha de clases.

Dejemos hablar al propio Marx en una carta justificadamente célebre que dirige a un amigo residente en los EE.UU.:

No deben atribuirme el mérito de haber descubierto ni la existencia de las clases en la sociedad moderna, ni la lucha de clases que llevan entre ellas. Historiadores burgueses mucho antes que yo describieron el desarrollo histórico de esta lucha de clases y economistas burgueses expusieron su anatomía económica. Lo que hice nuevo es demostrar: 1) que la existencia de clases está ligada a fases históricas determinadas del desarrollo de producción; 2) que la lucha de clases conduce necesariamente a la dictadura del proletariado; 3 ) que esta dictadura no constituye sino la abolición de todas las clases hacia una sociedad sin clases (Rubel, 1957: 257)

En 1849, en El Manifiesto Comunista, y en 1851, El 18 Brumario de Luis Napoleón Bonaparte, y en la introducción a la Critica de la Economía Política de 1857, anticipo de El Capital, y aun en su obra mayor inconclusa: en todas estas obras, explícita o implícitamente, Marx apunta también a la transformación revolucionaria de la sociedad a partir de la lucha de clases.

Llamará sujeto histórico al responsable estratégico de la destrucción definitiva de la sociedad de clases, a un proletariado universal sin fronteras. No es una elección ideológica o moral sino una consecuencia natural del propio sistema capitalista condenado, de la situación de clase. Para que esta tarea se lleve a cabo será necesario que esta clase social tome conciencia de su posición y de su misión histórica.

La sociedad industrial europea no es homologable a las sociedades industriales que aparecían en América Latina, aunque perfilaban lo que ahora (en el siglo XXI) conocemos como sociedad planetaria, que pone a ambos en un nivel de consideración diferente. La sociedad industrial se está extinguiendo, reemplazada por la sociedad de servicios, de la información, de la multiculturalidad. El antiguo sujeto histórico como veremos, está ahora en discusión. 


\section{Notas}

(1) Razón en sentido lato. Una reflexión adecuada para lo que aquí se discute se encuentra en Chatelet (1992) en particular páginas 190 en adelante.

(2) El romanticismo revolucionario no es solo un estilo, sino un contenido que altera el significado de la revolución hasta cambiar radicalmente el concepto central teórico y práctico como es el sujeto histórico.

(3) Shanin tuvo impacto tanto en Europa como en América Latina. Especialmente un joven antropólogo argentino fallecido tempranamente divulgó la recuperación que éste hacía de Chajanov como puede verse en Eduardo Archetti (1978) «Una visión general de los estudios sobre 1 campesinado» Estudios Rurales Latinoamericanos, volumen 1 número 1, Clacso, Buenos Aires.

(4) No me ocupo de la cuestión ni de su seguimiento muy bien hecho por lo demás por José Arico, pero como se advierte estoy incluyendo invariablemente en la reflexión las referencias a nuestra región, porque las historias intelectuales en las ciencias sociales, para ser exhaustivas reclaman una consideración distinta a la habitual

(5) Cfr. las intensas discusiones en Lucio Colletti (1978) presentado por José Arico.

(6) No me ocupo aquí ni de las contribuciones del debate sobre la modernidad que transcurre los últimos doscientos años pero sugiero una lectura de Darío Martucelli (1999) y su Sociologie de la Modernité donde examina las contribuciones al debate de los más reconocidos sociólogos europeos y norteamericanos, que reunidas a las sólidas reflexiones de Nicolás Casullo desde América Latina ofrecen un buen panorama inicial para ambos lados del Atlántico.

\section{Bibliografía}

BERMAN, Marshall (2003), Aventuras Marxistas. Buenos Aires: Siglo XXI.

CASULLO, Nicolás (1999), Itinerarios de la modernidad. Buenos Aires: Eudeba.

CHÂTELET, François (1992) Une histoire de la raison. Paris : Du Seuil

COLLETTI, Lucio (1978), El marxismo y el «derrumbe» del capitalismo. México: Siglo XXI.

DELICH, Francisco (1971), Coyuntura y Estructura. Córdoba: Facultad de Ciencias Económicas, Universidad Nacional de Córdoba.

DELICH, Francisco (2004), Repensar América Latina. Barcelona: Gedisa.

DELICH, Francisco (2006) Sociedades Invisibles. Barcelona: Gedisa.

HOOK, Sidney (1972), Da Hegel a Marx. Firenze: Sansoni. 
HUNT, Tristram (2011), El gentleman comunista. La vida revolucionaria de Federico Engels. Barcelona: Anagrama.

KOLAKOWSKI, Leszek (2005), Main currents of marxism. New YorkLondon: W.W. Norton \& company

LEFEBVRE, Henri (1962), Introduction a la Modernité. Paris : De Minuit.

MARTUCELLI, Danilo (1999), Sociologies de la modernité. Paris : Gallimard.

MARX, Karl (1952), La guerre civile en France-1871. Paris : Editions Sociales.

MARX, Karl (1963), Le 18 Brumario de Luis Napoleón Bonaparte. Paris: Editions sociales.

MARX, Karl (1963), Oewvres. Paris, Gallimard

MARX, Karl (1969), Cartas a Kugelman. Buenos Aires, Avanzar.

MARX, Karl (1980), El Capital. Crítica de la Economía Política. México, Fondo de Cultura Económica.

MARX, Karl y ENGELS, F. (1980), Teorías sobre la Plusvalía. México, Fondo de Cultura Económica.

MARX, Karl y ENGELS, F. (1986), Manifiesto del Partido Comunista. Buenos Aires, Anteo.

MILLS, Charles W. (1960), Listen Yankee Ballantine,B.York

MILLS, Charles W. (2000), C. Wright Mills Letters and autobiografical Writings. California, University and California Press.

POTIER, Jean-Pierre (1994), Piero Sraffa. Valencia, Edicions Alfons el Magnanim.

REINHARDT, Ark (1997), The art of being free. Taking liberties with Tocqueville, Marx and Arendt. New York, Cornell University Press.

RUBEL, Maximilien (1957), Karl Marx. Essai de Biographie Intelectuelle, Paris, Marcel Riviêre.

RUBEL, Maximilien (1974), Marx critique du marxisme. Paris: Payot.

SILVA, Ludovico (1971), El estilo literario de Marx. México, Siglo XXI.

SHANIN, Teodor (1971), Peasants and Peasant societies. London, Penguin.

SWINGEWOOD, Alan (1975), Marx and modern social theory. London, Mc. Millan press. 